\title{
THE CO-EVOLUTION OF EQUITABLE TERTIARY EDUCATION IN A GLOBAL NETWORKED SOCIETY: THE CASE OF THE OERU
}

\author{
Daniele Dubien, Niki Davis, University of Canterbury, Wayne Mackintosh, OERu, New \\ Zealand
}

\section{Introduction}

The continuing evolution of ubiquitous learning technologies and networks is reshaping models of learning with increasing potential for underserved populations of learners who cannot afford tertiary education. This paper presents a case study of innovative highly networked organisation called the "Open Education Resource universitas" (OERu).

As the theme of EDEN 2019 conference has recognised, "Technology is with us everywhere which validates the horizontal-holistic approach for imperative questions of the period. For the transforming education landscape, challenges come increasingly from the socio-culturaleconomic, structural and policy fields. Education has to be visionary to reach efficiency gains, new sources - and to offer sustainable services, reflecting the complexity of modern societies." The OERu is on the far left of such visionary developments with a radically open approach to its equitable mission to expand higher education to come within the reach of all of students who are likely to remain underserved.

Established in 2011, the OERu as an educational organisation is co-evolving with cutting edge technologies such as, micro-learning, alternative digital credentials, and implementation of an open source Next Generation Digital Learning Environment (NGDLE) (Brown, 2017). Its strategy is to evolve by scaling up with partners worldwide. Innovations already documented include a successful small mOOC (Davis \& Mackintosh, 2013). This case study plots the OERu in Niki Davis' (2018) Arena Framework to clarify the complexity of the evolution of this organisation. The findings aim to support the OERu and its partners to fulfil their vision of providing affordable access to education.

\section{Background}

According to UNESCO, demand for higher education increases globally by approximately $1 \%$ each year (Marginson, 2016). This demand will stimulate further coevolution of educational organizations and educational technologies. Along with the increasing demand for higher education is a desire for equality, which can be partially attained through access to higher education (Marginson, 2016). One option for helping to fill this demand is to use open educational resources (OERs) (William and Flora Hewlett Foundation, 2019). OERs are widely available, as are guides for their adoption (e.g. UNESCO \& COL, 2015). 


\section{Theoretical Framework}

Since 2005, drawing on the increasing knowledge of change with technology in education and human ecology, Davis (2018) has developed her Arena Framework to clarify the worldwide scope of the complexity of the co-evolution of education and digital technologies. Concepts and terminology used in ecology are used extensively within this framework. For example, many Arenas have as their central ecosystem inhabited by a class of learners, their teacher and their learning resources, including physical and digital spaces as shown in the generic Arena in Figure 1. In order to clarify the influences on the learning ecosystem, the systems in considered in five sectors: resource, professional, community, bureaucratic and political (see Figure 1).

The whole Arena Framework depicts the interaction of education systems worldwide as being contained within a sphere, the global ecosphere of education. Within that global ecosphere layers of ecosystems can be mapped; the nationwide ecozones contain the national educational systems of each country, such as the USA and New Zealand. Embedded within each of those nationwide ecozones are many millions of ecosystems inhabited by students and their teachers. Many, but not all, of the ecosystems nest in layers, one completely within the other. However, ecosystems in which digital applications evolve are unlikely to be embedded; instead they spread across many ecosystems and often globally. One Arena inhabited by the OERu centred on the ecosystem inhabited by an OERu course development team is illustrated later in this article.

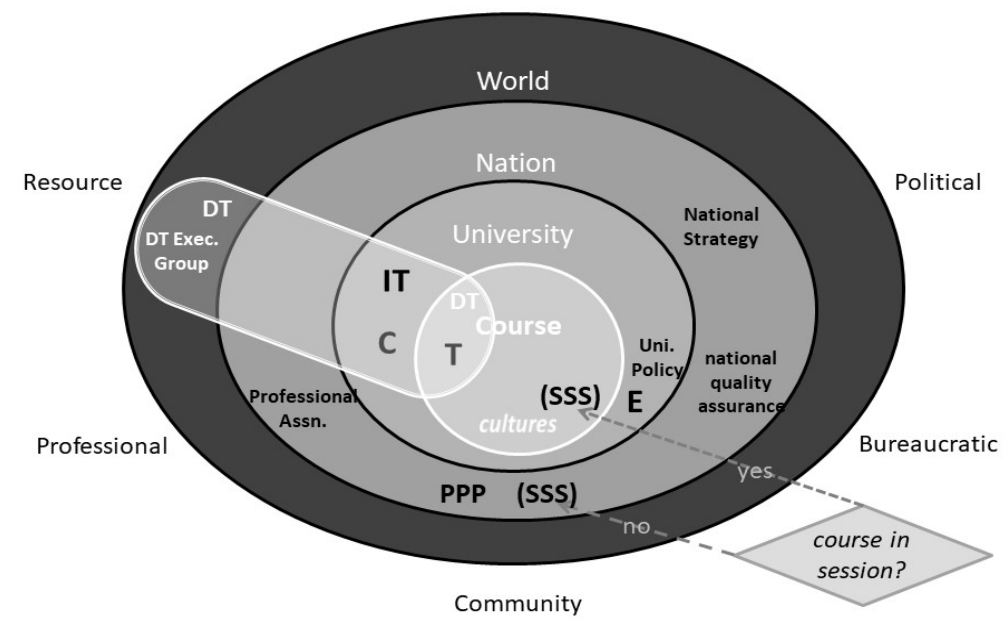

Figure 1. An Arena with one teacher and her course ecosystem in a university at the centre of the global ecosphere. It also includes the ecosystem of an organisation that provides Digital Tools (DT). The course has two phases, in session with students in the ecosystem and out of session without students.

Key: Teachers (T), Parents (P), Students (SSS), Executive managers (E), technical support staff (IT), Colleagues including Educational Technologist (C), Digital Tool or service (DT).

The Arena Framework goes beyond human ecology to recognise that behaviour of the various roles of the people in each ecosystem evolve in a similar way to the human ecologist's conception of species. The most common roles in education are teacher, learner, educational 
technologist, librarian, technician, and last but not least executive, so these are the common species in Arena ecosystems. There is also non-living matter in ecosystems, which includes books, furniture, and mobile devices that connect the species through Cloud-based ecosystems. Thus educational ecosystems are often a blend of the physical and digital world; one percolates the other (Gillen et al, 2018). The teacher is recognized as the keystone species' in a learning ecosystem inhabited by students in a traditional university because of the dominance of that role on behaviour in that ecosystem; the learning ecosystem is disrupted when a teacher leaves (unless there has been collaborative preparation for the transition), but the same is not true for a learner or a technician. Other keystone species can be identified in different types of ecosystems: the parental role is a keystone species in a family ecosystem. Similarly, the executive is a keystone species in a business organisation, whereas a technician is not. However, the inhabitants of an ecosystem change with its phases and these roles evolve over time (as do educational technologies) and, as they do, they influence one another. Thus co-evolution of education and technology deserves more research, and the Arena Framework is useful to frame such research.

\section{Methodology}

Data about organizational culture and processes were collected through interviews with OER developers, analysis of literature pertaining to the OERu and its partners, online planning documents, course content, and observations of meetings (synchronous and asynchronous). The data set includes 12 interviews with 8 people plus more than 50 documents and over five observations including online meetings. The data collection period was two years from October 2016, particularly 2017 when the course was under development for the first time. The analysis consisted of identifying patterns of different behaviour and identifying all living and non-living matter. In addition to other analyses the data was mapped within the global Arena Framework (Davis, 2018). A few of the behaviours most pertinent were selected to illustrate the behaviour in the ecosystems, especially the behaviour of keystone species.

\section{Findings: The Case of the OERu}

The OERu is mapped in an Arena Framework in 2017 (see Figure 2) was developed to encompass all the ecosystems in the ecosphere within which the selected "Learning in a Digital Age" (LiDA) course was being developed. It should be noted that the radically open processes of the OERu design process lead us to estimate some of the actors and behaviour where it cannot be "seen" such as when a participant may have decided not to take action in response to an OERu communication. We begin with the central course ecosystem and work outwards to the global ecosphere.

\section{The LiDA Course Ecosystem During the Design Phase}

"Learning in a Digital Age" (LiDA) (OERu, n.d.) aims to help students develop technological and critical thinking skills and to prepare students for subsequent online studies to enable higher achievement while also reducing attrition. This course is part of the Certificate in General Studies and the Certificate of Higher Education (Business); certificates that equate to 
a first year of study in a general Bachelor of Arts and Business degree respectively. The modular design of the course and the programme supports open education. It is interesting to note that by January 2019 OERu partner universities in four countries offer graduates of this course credit in one of their programmes.

The living species in this course design ecosystem included both employees of the OERu, the director (acting in the roles of subject matter expert, educational technologist and course leader) and the open source technologist (on request). Another expert educational technologist also supported this course development for a time. Periodically the course leader invited OERu supporters to contribute through calls on open online forums and social media. The course was developed openly in WikiEducator and other non-living matter included content and curriculum ideas from two OERu partners (OERu, 2017). The behaviour in this ecosystem was very "agile" (the term here is used in the sense of agile design (Brown, 2017). For example, the development team used an online Kanban software tool (WeKan) to brainstorm the curriculum outline and then progressed course design and development using an open wiki (WikiEducator) The approach had been described by the course leader in the earlier planning curriculum phase during an online meeting in June 2016 when he said:

"What I'm proposing we do [...] anybody who wants to be involved in this process, we'll develop those micro-course outlines [...] We will be doing that in the wiki. Anybody will be able to see and comment and add and tweak, but I'm aiming to get to the point where we can have a curriculum outline within 7 to 10 working days. We will of course take in any feedback we receive. But I should also just add... It's a very open source approach that we use. We work on a model of rough consensus and running code. What that means - you would have seen that in action here - we try and achieve a rough consensus and then we implement things and get things done. We don't go into eighteen months of deliberation around a particular point. If you aren't at the table to make a decision, you've got to accept the decision that the folk around the table are taking. The people that are actively involved are the folk that determine how this thing goes forward. So, if you do want to shape the future of this development, I strongly advise that you be involved because in ten days' time, there's going to be an outline and we're going to implement it. So, at the risk of sounding like a benevolent dictator, I just want to open it to the floor and just make sure we are comfortable with that approach: rough consensus and running code. This is not a democracy. We don't work with $50 \%+1$. If there are three people at the table those are the people who are going to take the decision (57:54 - 59:55)" (OERu, 2016b).

The course design process also helped to focus OERu's crowd sourcing innovations. For example, the OERu launched a crowdsourcing activity using a WikiEducator page (OERu, 2016c), a discussion forum (OERu, 2016a), and Twitter (OERu, 2016d). Based on similar courses from partner institutions, the course leader selectively integrated the crowdsourced 
suggestions into the LiDA curriculum. He presented the resulting course curriculum in an online meeting and requested feedback from the participants, making changes instantly on the online Kanban board hosted by OERu (2016b).

This OERu course is one of the courses that are called 'open boundary' courses because they include two types of student: (a) credited learners who register, pay for assessment, and earn credit upon successful completion of course requirements; and (b) non-credited learners who participate informally without seeking assessment. Both can participate in the course and communicate with one another. This tends to increase in student-student interactions which can increase both technical and subject-matter support, plus an enriching experience given the variety of student perspectives. This flow of communication was designed to be controlled so that the students would not become overwhelmed. The ecosystem changed into its course phase 14/3/18 - 14/6/18 for its first successful offering. The OERu's 2018 mid-year report indicated the reach of this offering,

"Of the 703 registered participants from 60 different countries, the top thirteen countries according to the number of registrations were: India, United States, Canada, Fiji, Nigeria, New Zealand, Papua New Guinea, South Africa, Uganda, Australia, Egypt and Kenya. Site analytics recorded 1,362 users visiting the course websites during the active cohort period, indicating that $48 \%$ of visitors chose not to register for course announcements. The course sites generated 19,839 page views with 9,083 being unique for the active cohort periods" (OERu, 2018; p.5).

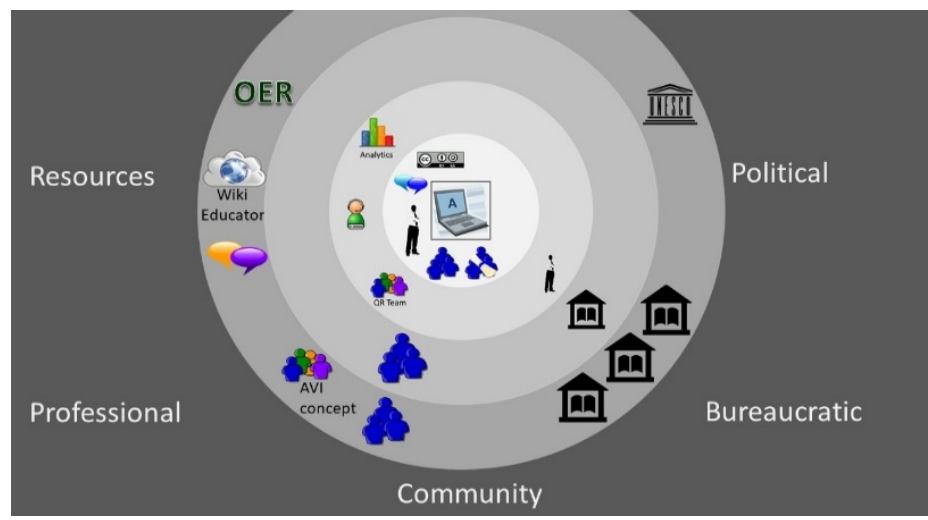

Figure 2. The OERu in Davis' Arena Framework, with the ecosystem of a course under development at the centre of the global ecosphere

\section{The OERu Technical Ecosystem}

As shown in Figure 2 the OERu technical system shown surrounding the course ecosystem has adopted and adapted a range of open source software tools in its platform (Technology Stack). The first tool was WikiEducator used for collaborative authoring, and in 2016 and 2017, the OERu used Kanban boards to structure the LiDA curriculum in an agile fashion. The course site was published in WordPress which contained links to tools for studentstudent interaction such as discussion forums on the Discourse platform, hypothes.is which is an application for social annotation of web pages, bookmarks.oeru.org which uses Semantic 
Scuttle - a social bookmarking tool, Mastodon which is for microblogging, and WENotes (WikiEducator Notes) which aggregates all the posts that contain specific tags mentioned in the course and emails to the students. In addition to these tools that are linked throughout the course, students are recommended to use open source blogs such as WordPress which is used as the course platform, or Medium and Blogger. This practice allows the students to maintain control over their course contributions during and after the course session. The OERu would normally invite students to send in their blog URLs and aggregate them into a blog feed. However, this practice was not used in this offering of LiDA.

The keystone species in this ecosystem is the open source technologist employed by the OERu who ensures orderly behaviour in this evolving system, adapting tools on request and updating their fit as they evolve. The range of tools in the OERu Technology Stack has greatly expanded since the first OERu mini course was piloted by Davis and Mackintosh (2013). The OERu both adopted and adapted these tools to work together coherently (OERu Technology, 2018). Further analysis would be needed to identify if that has impacted the evolution of these tools in other contexts, which is to say whether this co-evolution of education and technology has spread beyond the OERu.

\section{The OERu ecosystem}

The OERu aims to cover much of the global ecosphere, rather than be limited to one ecozone. However, it is notable that is domiciled in New Zealand and therefore subject to the laws of that country as well as international law. By 2017 it had over 25 partners in 8 countries. The $\mathrm{OERu}$ uses an open business model with transparent planning processes aimed at sustainability. It is " $[a] n$ international network of recognised partner institutions from five continents - providing top-quality tertiary courses to students everywhere" (OERu, n.d., para. 1). In 2017 the OERu employed only two staff, the OERu director is the chief executive and therefore the only the member of keystone species. However, it is important to note that many other people acting in a number of roles contributed to the behaviour in this ecosystem and the director reports to the OER Foundation Board.

As described earlier the OERu has "radically open" behaviour in which staff from partner institutions attend OERu consultations and participate in informing and making decisions. One instructional designer employed in a partner institution and regularly involved in OERu activities including this course design was interviewed. He also saw the intended culture as one that is "fully open and allows for shared learning". However, he believed that the intended culture was somewhat different from the actual culture where a core group of people drive the OERu's activities. This aligned with the chief executive's view of the encompassing OER Foundation's (OERF) approach to leadership, which he described in this way:

"Meritocracy is a guiding principle of the OERF. Leadership roles in our community projects are 'earned' through sustained performance. Individuals who have gained respect from their community peers through engagement 
have a greater influence on decision-making. Transparent planning promotes trust in our open decision-making practices" (Mackintosh, 2017; p.104).

Other species in the OERu were organised into working groups. For example, marketing working group prepared a case study of the LiDA course to market it and also to explain the OERu's approach to course design, and fit with OERu's first year of study (see https://oeru.org/news/learning-in-a-digital-age/).

\section{Discussion}

Davis' Arena Framework was applied successfully to map the actors and networks of this highly networked global organisation that aims to evolve agile equitable higher education. The ecosystems briefly described here showed various ways in which the various living and non-living species influence the activities of the $\mathrm{OERu}$, for example by inviting people to contribute ideas using specific digital tools. OERu courses have instructional designers as one of the keystone species during the design and development phases, and this species is unusually dominant when compared with traditional universities. For courses that are not facilitated by a teacher the course delivery phase, the keystone species has yet to be identified.

The analysis has also identified that students have two subspecies. Open boundary courses are designed to include credited and non-credited students who interact for an enriching experience and for support. The two types of students will behave in different ways, depending on their goal to earn credit, or not. Davis and Mackintosh (2013) describe an early OERu open boundary course module that was identified as a community approach micro Open Online Course (mOOC). The course designer and most influential educational technologist (Mackintosh) was the same person as in this LiDA course. It provided evidence that including the two subspecies of students could enrich the course ecosystem during its delivery phase to enhance learning as well as intensive professional development for a teacher who had much to learn about open course design.

These findings demonstrate some of the possibilities and realities of open processes and in this way our findings may help to manage expectations. Staff who are aiming to develop courses as OER may be able to better grasp the additional potential and challenges of working with radically open course design, development, and delivery. Current and prospective members of the OERu may be able to consider the species and matter that can become involved when starting to design and offer innovative open courses. The extraordinary openness of the OERu enables new partners to offer credit for open courses before they engage in designing one.

We plan to continue this research into LiDA and the OERu, including the co-evolution of the digital tools that have been deployed. Possibilities for future research and development include analysis of ecosystems for a variety of OERu courses plotted on an Arena and compared to find trends and changes over time as courses are designed, launched and revised. 


\section{References}

Brown, M. (2017). THE NGDLE: We are the architects. EDUCAUSE Review, 52(4), 11. Retrieved from https:/library.educause.edu/topics/teaching-and-learning/nextgeneration-digital-learning-environment-ngdle

Davis, N. E. (2018). Digital technologies and change in education: The arena framework. London \& New York: Routledge.

Davis, N. E., \& Mackintosh, W. (2013, November). A mOOC prepared to make a difference. DEANZ Magazine, 1-7.

Mackintosh, W. (2017). Open course development at the OERu. In R. Jhangiani \& R. BiswasDiener (Eds.), Open: The philosophy and practices that are revolutionizing education and science (pp. 101-114). London: Ubiquity Press.

Marginson, S. (2016). The worldwide trend to high participation higher education: Dynamics of social stratification in inclusive systems. Higher Education, 72(4), 413-434. Retrieved December 1, 2018, from https://link.springer.com/article/10.1007/s10734-016-0016-X

OERu (n.d.). OERu partners. Retrieved December 1, 2018, from http://oeru.org/oeru-partners

OERu (n.d.). Learning in a digital age. Retrieved February 2, 2019, from https://oeru.org/learning-in-a-digital-age/

OERu (2016a). Crowdsourcing topics for inclusion in the Learning in a Digital Age (LiDA) course. Retrieved January 15, 2019, from http://groups.oeru.org/groups/lida-courseteam/messages/topic/7dmqEphNaBlF8hyi34DuA2/

OERu (2016b). Learning in a digital age/1st Meeting. Retrieved January 15, 2019, from http://wikieducator.org/Learning_in_a_digital_age/1st_Meeting

$\mathrm{OERu}$ (2016c). Learning in a digital age/Crowdsourcing topics for LiDA. Retrieved January 15,2019 , from http://wikieducator.org/Learning_in_a_digital_age/Crowdsourcing_topics_for_LiDA

OERu (2016d). \#oerulida. Retrieved January 15, 2019, from https://twitter.com/hashtag/oerulida

OERu (2017). Learning in a digital age/Curriculum planning. Retrieved February 4, 2019, from http://wikieducator.org/Learning_in_a_digital_age/Curriculum_planning

OERu Technology (2018, October 31). 2018 update on the OERu Technology Stack [blog post]. Retrieved February 4, 2019, from https://tech.oeru.org/2018-update-oerutechnology-stack

UNESCO, Commonwealth of Learning (2015). Guidelines for open educational resources (OER) in higher education. Vancouver: COL \& UNESCO. Retrieved December 1, 2018, from http://oasis.col.org/handle/11599/60

William and Flora Hewlett Foundation (2019). Open Educational Resources. Retrieved February 4, 2019, from https://hewlett.org/strategy/open-educational-resources/ 


\section{Acknowledgements}

Thanks to all of those who have contributed to the LiDA course and the establishment of the OERu. This article retains the Creative Commons licence adopted by OERu. The University of Canterbury membership of OERu was a project of the e-Learning Lab from 2012-2104. We also acknowledge Danielle Dubien's Commonwealth Scholarship and Fellowship Plan (CSFP) PhD scholarship. @ $@$ This work is licensed under a Creative Commons Attribution 4.0 International License. 